\title{
Visible and near-infrared spectroscopic analysis of raw milk for cow health monitoring: Reflectance or transmittance?
}

\author{
B. Aernouts, ${ }^{1}$ E. Polshin, J. Lammertyn, and W. Saeys \\ Division of Mechatronics, Biostatistics, and Sensors, Department of Biosystems, Katholieke Universiteit Leuven (BIOSYST-MeBioS K.U.Leuven), \\ Kasteelpark Arenberg 30, 3001 Leuven, Belgium
}

\begin{abstract}
The composition of produced milk has great value for the dairy farmer. It determines the economic value of the milk and provides valuable information about the metabolism of the corresponding cow. Therefore, online measurement of milk components during milking 2 or more times per day would provide knowledge about the current health and nutritional status of each cow individually. This information provides a solid basis for optimizing cow management. The potential of visible and near-infrared (Vis/NIR) spectroscopy for predicting the fat, crude protein, lactose, and urea content of raw milk online during milking was, therefore, investigated in this study. Two measurement modes (reflectance and transmittance) and different wavelength ranges for Vis/NIR spectroscopy were evaluated and their ability to measure the milk composition online was compared. The Vis/NIR reflectance measurements allowed for very accurate monitoring of the fat and crude protein content in raw milk $\left(\mathrm{R}^{2}>0.95\right)$, but resulted in poor lactose predictions $\left(\mathrm{R}^{2}<0.75\right)$. In contrast, Vis/NIR transmittance spectra of the milk samples gave accurate fat and crude protein predictions $\left(\mathrm{R}^{2}>0.90\right)$ and useful lactose predictions $\left(\mathrm{R}^{2}=0.88\right)$. Neither Vis/NIR reflectance nor transmittance spectroscopy lead to an acceptable prediction of the milk urea content. Transmittance spectroscopy can thus be used to predict the 3 major milk components, but with lower accuracy for fat and crude protein than the reflectance mode. Moreover, the small sample thickness $(1 \mathrm{~mm})$ required for NIR transmittance measurement considerably complicates its online use.
\end{abstract}

Key words: visible and near-infrared spectroscopy, milk, dairy management, health monitoring

Received March 10, 2011.

Accepted July 23, 2011.

${ }^{1}$ Corresponding author: Ben.Aernouts@biw.kuleuven.be

\section{INTRODUCTION}

Cow milk and derived products are important components in the Western diet. The composition of raw milk largely determines its nutritional value and the physicochemical properties during milk treatment and processing. Therefore, milk composition is important for the milk industry and the consumer. Beside this, the composition (mainly fat and protein content) and quality (e.g., udder health by SCC) defines the economic value of the milk and, with that, also the income of the farmer. Moreover, the composition of the extracted milk contains valuable information about the metabolic status of the cow, due to the very intensive interaction between blood circulation and milk production (Bramley et al., 1992). Therefore, the concentration and total production of the different milk components can act as a diagnostic tool for monitoring individual cow health and nutritional status (Hamann and Krömker, 1997). For example, the urea content, together with the protein content of the produced milk, indicate the balance between protein and energy in the rumen and can be used to optimize the efficiency of nitrogen utilization (Frank and Swensson, 2002). Some milk composition parameters could also be involved in the detection of metabolic disorders induced by an unbalanced diet (Mulligan et al., 2006). A high ratio of milk fat-tomilk protein percentage can be used as an indicator for dairy cattle with a high risk of negative energy balance and related affections like ketosis, displaced abomasum, ovarian cyst, lameness, mastitis, and body condition loss (Friggens et al., 2007). Milk fat depression could imply subacute ruminal acidosis (Plaizier et al., 2008). Changes in the milk composition (e.g., somatic cells, lactose, minerals, and enzymes) can also be attributed to a disease-combating response of the cow in the case of mastitis, decreased secretory activity, and alteration of the blood-milk barrier (Mulligan et al., 2006).

Today's economic reality forces dairy farms to further grow, specialize, and become more efficient. Thanks to continued genetic selection and improvement in feed quality and management on the farm, milk production per cow has increased considerably over the last de- 
cades. A downside of this evolution is that these highly productive cows are more sensitive to the production diseases mentioned above. Because a precondition for increased profitability of dairy farming is an increase in both the lactation and lifetime production per cow, more effective prevention and early diagnosis and treatment of affections or deficiencies is needed (Hamann and Krömker, 1997). Individual cow health, diet, and udder status should be monitored carefully to meet these demands, decrease financial losses, and secure welfare in dairy farming.

Nowadays, basic milk components (fat, protein, lactose, and urea) of individual cow milk samples are analyzed once every 3 or $4 \mathrm{wk}$ as part of milk-recording systems. For accurate individual cow health and diet management a considerably higher sampling rate would be necessary. Measuring the individual milk composition at every milking would promote early detection of systemic and local alterations, thus providing a great input for strategic and management decisions (Friggens et al., 2007). This is only possible if milk composition is analyzed online, during milking.

Visible and near-infrared (Vis/NIR) spectroscopy is a valuable technique for rapid, non-destructive, and online analysis of the quality and composition of agricultural products (Saeys et al., 2005; Nicolaï et al., 2007; Huang et al., 2008). Several researchers have shown the potential of Vis/NIR spectroscopic analysis of raw milk in the reflectance, transmittance, or transflectance mode for reliable determination of the fat, protein, and lactose concentration in the laboratory (Laporte and Paquin, 1999; Purnomoadi et al., 1999; Tsenkova et al., 1999; Jankovská and Šustová, 2003; Navrátilová et al., 2006; Saranwong and Kawano, 2008). For the analysis of milk, most researchers have used Vis/NIR-transmittance spectroscopy with an optical path length ranging from 0.5 to $15 \mathrm{~mm}$ depending on the wavelength range considered. When measurements were limited to the Si range $(400-1,100 \mathrm{~nm})$ best results were obtained with a path length of $10 \mathrm{~mm}$ (Tsenkova et al., 1999) to 13.6 mm (Saranwong and Kawano, 2008). Due to the high absorption by water in combination with the strong light scattering by the fat globules in raw milk, the optimal path length for the 1,100 to 2,500-nm range was found to be 0.5 to $1 \mathrm{~mm}$ (Laporte and Paquin, 1999; Purnomoadi et al., 1999; Tsenkova et al., 1999). The need for such a small path length considerably complicates online use of transmission measurements on a milking system. This small opening could slow down the milk stream and, therefore, influence the vacuum in the milking tube. Vacuum fluctuations should be avoided, because these could lead to release of the milk cluster, teat damage, and respray (Bramley et al., 1992). Regardless of these disadvantages, several researchers tested online (diffuse) transmittance (600$1,050 \mathrm{~nm}$ ) measurement of milk and reported promising results (Kawamura et al., 2007; Kawasaki et al., 2008). Because cheese and milk powder are too dense to measure Vis/NIR transmittance, reflectance measurements are typically used (Barabássy, 2001; O'Callaghan et al., 2002). Reflectance spectroscopy does not pose any limitations on the size of the measurement cell, which can be a considerable advantage for online measurement of biological fluids (Saeys et al., 2005). However, only few researchers have tested its usefulness for milk composition measurement. Jankovská and Šustová (2003) used Vis/NIR reflectance spectroscopy to analyze raw milk samples. They obtained better predictions for the $\mathrm{CP}$ content, but worse for the fat and lactose content compared with those obtained in transmittance mode by Tsenkova et al. (1999) or Saranwong and Kawano (2008). However, from the literature, it cannot be concluded which measurement mode (reflectance or transmittance) and wavelength range are most suitable for online milk composition measurement using Vis/NIR spectroscopy. No objective comparison of the measurement modes and wavelength ranges has been reported so far. Therefore, the main objective of this study was to investigate whether Vis/NIR reflectance or transmittance spectroscopy of raw milk resulted in the best prediction of the milk composition. This was done by measuring both spectra on the same set of raw milk samples, building partial least squares (PLS) regression models to predict their fat, $\mathrm{CP}$, lactose, and urea content and validate these models on an independent set of test samples. Afterward, these results were used to investigate and statistically compare the potential of Vis/NIR reflectance and transmittance spectra for predicting the major components in raw milk.

\section{MATERIALS AND METHODS}

\section{Milk Samples}

The milk samples used in this study for both calibration and validation were collected in the context of a milk production registration (MPR) system. Dairy farmers from all over Flanders (Belgium) can participate in this system to monitor the milk composition and production of their individual cows. Every 4 wk a representative milk sample $(27 \mathrm{~mL})$ is collected from each cow, preserved $\left(4^{\circ} \mathrm{C}\right.$ and $0.11 \%$ vol/vol preservative; Qlip N.V., Leusden, the Netherlands) and analyzed within $3 \mathrm{~d}$ after sampling. Milk fat, CP, lactose, and urea content are examined by the use of the Milkoscan FT+ (Foss A/S, Hillerød, Denmark) according to ISO 9622:2000 (ISO, 2000). Additionally, SCC is determined by flow cytometry (Fossomatic; Foss 
Table 1. Basic statistics and intercorrelations $\left(\mathrm{R}^{2}\right)$ for all milk components in the selected calibration set (200 milk samples)

\begin{tabular}{|c|c|c|c|c|c|c|c|c|}
\hline Component & Mean & $\mathrm{SD}$ & Minimum & Maximum & \multicolumn{4}{|c|}{$\mathrm{R}^{2}$} \\
\hline Fat $(\%, w t / w t)$ & 4.48 & 0.76 & 2.72 & 7.94 & 1.00 & & & \\
\hline Lactose $(\%, \mathrm{wt} / \mathrm{wt})$ & 4.64 & 0.33 & 2.92 & 5.22 & 0.02 & 0.16 & 1.00 & \\
\hline Urea $(\mathrm{mg} / \mathrm{L})$ & 227.84 & 31.80 & 136 & 332 & 0.03 & 0.00 & 0.00 & 1.00 \\
\hline $\log _{10} \mathrm{SCC}\left(\log _{10}\right.$ cells $\left./ \mathrm{mL}\right)$ & 4.98 & 0.60 & 3.70 & 6.92 & 0.01 & 0.07 & 0.20 & 0.00 \\
\hline
\end{tabular}

A/S) to monitor udder health. The large variability in milk composition, origin, and farm-specific effects (management, feed, and genetics) of the MPR samples is representative of the variability an online milk sensor would have to analyze. Including this variation in the calibration data is essential to develop accurate and robust prediction models (Saeys et al., 2008). To cover a wide compositional range, 300 MPR raw milk samples were selected, originating from 300 different cows and 30 different farms in Flanders (Belgium). Samples from the same farm were kept together during every handling (collection, defining the test and the calibration sets, Vis/NIR spectroscopic analysis, and groupwise cross-validation) to avoid modeling these group-specific effects. The sets of raw milk samples were separated in a calibration set of two-thirds (200 samples) and a test set of one-thirds (100 samples) by applying the duplex algorithm (Snee, 1977) on the reference composition data. This was done to select calibration and test sets with comparable composition ranges and correlations (Tables 1 and 2).

\section{Sample Treatment}

The Vis/NIR spectra were acquired for the collected MPR milk samples within $2 \mathrm{~d}$ after reference analysis. In the meantime, the milk samples were stored at $4{ }^{\circ} \mathrm{C}$ to prevent bacterial spoilage. The transmittance and reflectance spectra were acquired in random order for all samples (10) per group, and the order of the groups was also randomized. Prior to the spectroscopic analysis, the milk samples were heated to $37 \pm 1^{\circ} \mathrm{C}$ in a hot water bath [type 1004; Gesellschaft für Labortechnik
mbH (GFL), Burgwedel, Germany] and stirred gently to retrieve a homogeneous emulsion. The silica cuvette and glass beaker, used respectively to measure the transmittance and reflectance spectra, were thoroughly cleaned with ethanol and water, and carefully dried in between consecutive milk sample measurements.

\section{Vis/NIR Reflectance Spectroscopy}

Reflectance spectra were acquired with a Zeiss Corona 45 VISNIR 1.7 diode array spectrometer combining a Si array (3.2-nm resolution in the 306.5 to $1,135.5-\mathrm{nm}$ range) with an indium gallium arsenide (InGaAs) array (6-nm resolution in the 944.5 to 1,710.9-nm range) and controlled by Aspect Plus 1.76 software (Carl Zeiss AG, Jena, Germany). A built-in OMK measurement head (Carl Zeiss AG) was used to acquire the diffuse reflectance spectra in a $45^{\circ}$ configuration for a $20-\mathrm{mm}$ diameter circular area of the sample. Because this instrument has no moving components and measures all wavelengths at the same time, it is very interesting for online use on the farm. Integration times of $46 \mathrm{~ms}$ (Si) and $49 \mathrm{~ms}$ (InGaAs) were used to maximize the signal-to-noise ratio without saturating the detectors and 50 spectra were averaged. Reference measurements were performed after every 10 milk samples, which corresponded to an interval of about $20 \mathrm{~min}$. A dark reference was obtained by covering the OMK measurement head with a black tube. A calibrated $20 \%$ reflectance standard (Labsphere Inc., North Sutton, NH) was used as a white reference, because the average reflectance of this reference was found to be closest to that of raw milk over the entire Vis/NIR range. Milk samples were

Table 2. Basic statistics and intercorrelations for all milk components in the selected test set (100 milk samples)

\begin{tabular}{|c|c|c|c|c|c|c|c|c|}
\hline Component & Mean & SD & Minimum & Maximum & \multicolumn{4}{|c|}{$\mathrm{R}^{2}$} \\
\hline Fat $(\%, w t / w t)$ & 4.61 & 0.83 & 3.29 & 6.84 & 1.00 & & & \\
\hline Lactose $(\%, \mathrm{wt} / \mathrm{wt})$ & 4.58 & 0.33 & 3.48 & 5.09 & 0.07 & 0.20 & 1.00 & \\
\hline Urea $(\mathrm{mg} / \mathrm{L})$ & 225.15 & 43.59 & 155 & 329 & 0.03 & 0.00 & 0.01 & 1.00 \\
\hline $\log _{10} \mathrm{SCC}\left(\log _{10}\right.$ cells $\left./ \mathrm{mL}\right)$ & 5.14 & 0.55 & 3.85 & 6.60 & 0.02 & 0.10 & 0.30 & 0.03 \\
\hline
\end{tabular}


measured from the bottom in a silica glass beaker (48$\mathrm{mm}$ diameter, 18-mm high) filled with $20 \mathrm{~mL}$ of milk.

\section{Vis/NIR Transmittance Spectroscopy}

Transmittance spectra were acquired with an ASD LabSpec Pro spectrophotometer (ASD Inc., Boulder, $\mathrm{CO}$ ), combining a Si diode array (1.4-nm resolution in the 350 to $1,000-\mathrm{nm}$ range; ASD Inc.) with a postdispersive scanning monochromator consisting of 2 peltier cooled InGaAs detectors (1,000 to 2,500-nm range with 2-nm resolution; ASD Inc.) and controlled by Indico Pro 3.1.6 software (ASD Inc.). Due to the high absorption of NIR radiation by water and the strong light scattering by the fat globules (diameter of $0.1-15$ $\mu \mathrm{m})$, the average transmittance through $1 \mathrm{~mm}$ of raw milk was found to be less than $1 \%$. To get sufficient light on the detectors a 1-mm cuvette (Quartz Suprasil 100-QS; Hellma Benelux, The Hague, the Netherlands) was used in combination with a $200-\mathrm{W}$ halogen light source (Fiber-Lite DC-950; Dolan-Jenner Industries Inc., Lawrence, MA). The detector amplification was optimized for an average milk sample and 100 scans of $0.1 \mathrm{~s}$ each were averaged. This optimal amplification was then used for all reference and sample measurements. Dark reference measurements were performed using the built-in shutter of the instrument. For the white reference measurements, $0.075 \mathrm{~mm}$ of PTFE (Polyflon Co., Norwalk, CT) was used, because this gave a sufficient transmission signal without saturating the detectors. The reference measurements were taken every 10 milk samples (40 min). The transmittance of the milk samples was measured through the 1-mm cuvette filled with $400 \mu \mathrm{L}$ of raw milk.

\section{Statistical Analyses}

For both Vis/NIR reflectance and transmittance spectra, the region below $400 \mathrm{~nm}$ was removed because the signal-to-noise ratio was too poor due to the low sensitivity of the Si detectors for this light. Although the transmittance of milk was measured up to 2,500 $\mathrm{nm}$, reflectance was only measured up to $1,700 \mathrm{~nm}$. To separate the effect of the measurement mode from the effect of the wavelength range, the transmittance spectra were also limited to the 400 to $1,700-\mathrm{nm}$ range. However, it was also investigated whether the additional wavelength range $(1,700-2,500 \mathrm{~nm})$ in the transmittance spectra would improve the results for predicting the different milk components. On the other hand, the potential of the short wavelength range $(400-1,000 \mathrm{~nm})$ alone was also considered because it can be measured by inexpensive $\mathrm{Si}$ detectors available on the market. This resulted in 9 classes, bilaterally compared on their prediction performance: 400 to $1,700 \mathrm{~nm}, 400$ to 1,000 $\mathrm{nm}$, and 1,000 to $1,700 \mathrm{~nm}$ for reflectance and transmittance and 400 to $2,500 \mathrm{~nm}, 1,000$ to $2,500 \mathrm{~nm}$, and 1,700 to $2,500 \mathrm{~nm}$ for transmittance.

The acquired spectra and reference analysis values (fat, CP, lactose, urea, and SCC content) of all 300 milk samples were imported into Matlab (The MathWorks Inc., Natick, MA) to be analyzed with the PLS toolbox 5.5 (Eigenvector Research Inc., Wenatchee, WA). Because of the very high absorption by water ( $\pm 86 \%$ in milk), very low reflectance or transmittance signals were obtained at 1,392 to $1,535 \mathrm{~nm}$ or at 1,890 to $2,010 \mathrm{~nm}$ and 2,392 to $2,500 \mathrm{~nm}$, respectively (Figure 1 and 2). Consequently, the spectra were truncated to remove those noisy regions.

The best spectral pre-processing was determined empirically for every combination of class and component (fat, CP, lactose, urea, and SCC), based on the prediction performance for the calibration samples in cross-validation. First, the spectra were transformed to reflectance/transmittance (no transformation), absorbance, or Kubelka-Munk (only for reflectance spectra). Then one of the following scatter correction methods was applied: baseline correction, multiplicative scatter correction (MSC), standard normal variates (SNV), or first and second Savitzky-Golay derivatives (SG1D, SG2D) with second polynomial order and with different number of smoothing points (from 9 to $51 \mathrm{~nm}$ with a step of $6 \mathrm{~nm}$ ). Interference removal by orthogonal signal correction (OSC) was then tested as a third step. Finally, the pre-processed spectra were mean-centered. For each combination of spectral preprocessing, the prediction performance of the corresponding PLS regression model was evaluated based on a groupwise cross-validation, where all samples of a group were either in the calibration set or the validation set. The model complexity was optimized by choosing the lowest number of latent variables for which the cumulative prediction error was not significantly worse than the lowest error obtained with up to 20 latent variables (Haaland and Thomas, 1988). The spectral preprocessing approaches were ranked by increasing root mean square error of cross-validation (RMSECV) and the preprocessing combining the smallest number of latent variables with absolute prediction errors not significantly $(\alpha=0.05)$ worse (by statistical paired $t$-test) than those obtained by the model with the lowest RMSECV, was chosen.

To determine whether some variables (wavelengths) could be removed to make the models more robust (fewer latent variables) and better performing (lower RMSECV), several variable selection methods were applied: variable importance in projection (VIP), interval PLS [iPLS, in both forward (FiPLS) and reversed 


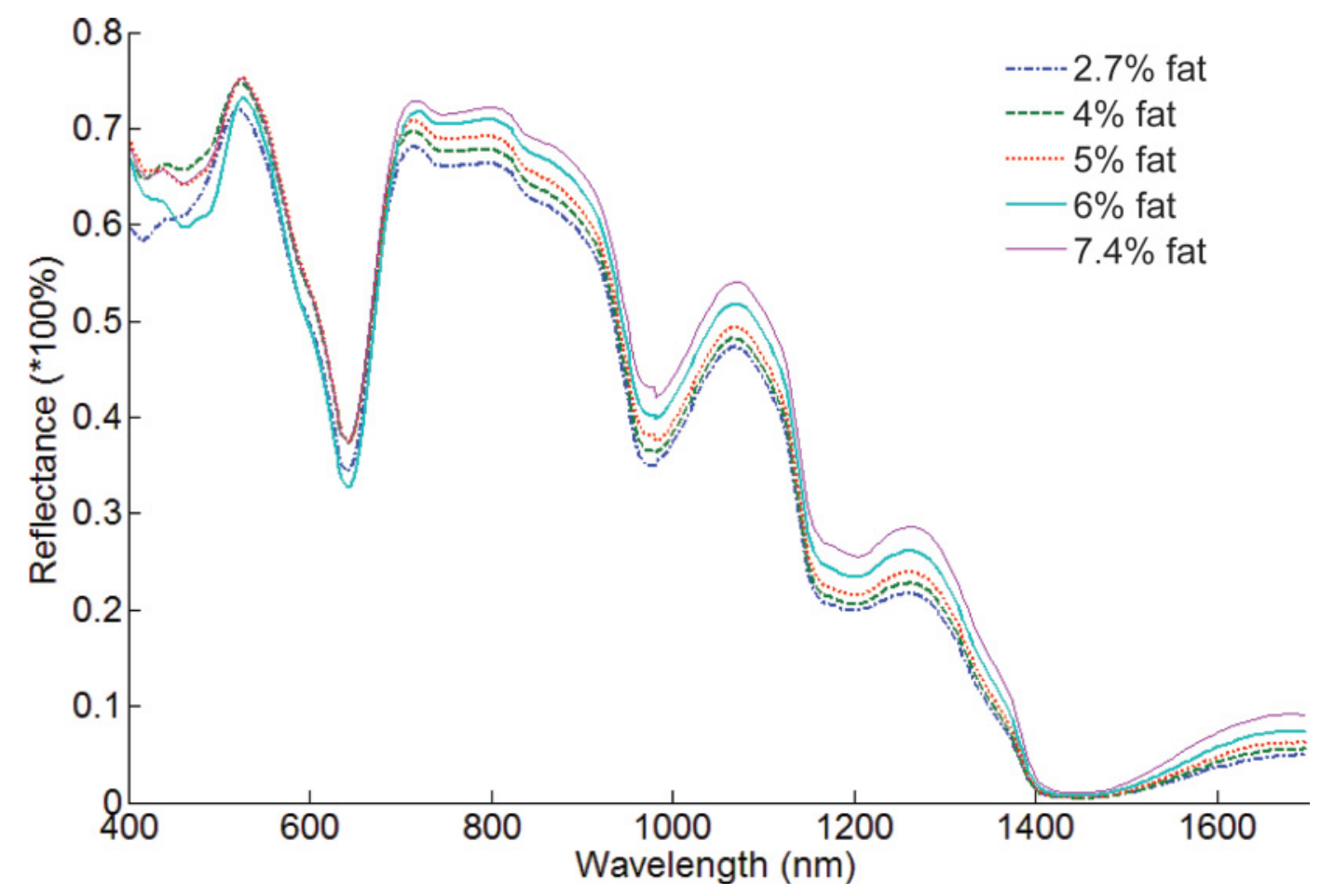

Figure 1. Raw reflectance spectra of 5 milk samples with different fat contents. Color version available in the online PDF.

(RiPLS) mode], and genetic algorithm (GenAl; Wise et al., 2006). The selected variables that led to the most parsimonious model whose prediction performance was not significantly ( $\alpha=0.05)$ worse than that of the model with the lowest RMSECV were selected to build the final model. These prediction models, which were

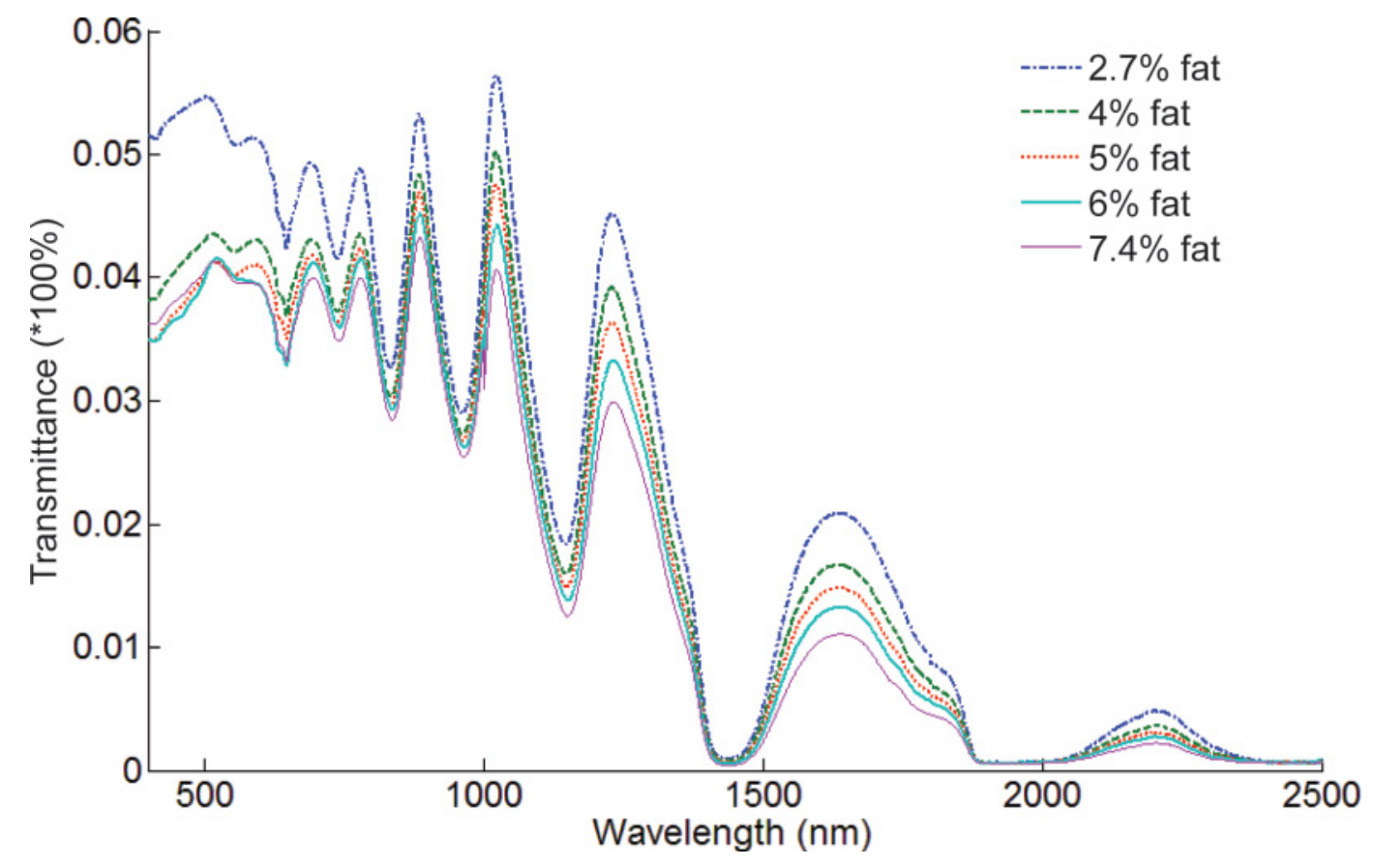

Figure 2. Raw transmittance spectra of 5 milk samples with different fat contents. Color version available in the online PDF. 
optimized based on their prediction performance in groupwise cross-validation on the calibration set, were then used to predict the concentrations in the samples of the test set. For evaluation of the prediction performance for the different components, the following statistical measures were included: the root mean square error (RMSE) and coefficient of determination $\left(\mathrm{R}^{2}\right)$ for both the cross-validation and the test set, together with the ratio of prediction error to standard deviation (RPD), bias, slope, and offset for the validation based on the test set (Tables $3-5$ ).

For a certain milk component, a 2-way ANOVA test was performed on the absolute prediction errors obtained for the test set to detect significant differences in the prediction performance between the different classes. The class was used as the first ANOVA factor, whereas the sample number was added as the second factor to make the test paired (Cederkvist et al., 2005). The different classes were compared with each other with Tukey Honestly Significant Difference (HSD) multiple comparisons if the factor class had a significant $(\alpha$ $=0.05$ ) influence on the model performance.

\section{RESULTS}

\section{Range of Calibration and Test Set}

The reliability, accuracy, and robustness of spectroscopic calibrations are restricted to the range of constituent values and the variation in measurement conditions taken into account during the calibration (Williams and Norris, 2001). The basic statistics of the different components in the calibration set considered are shown in Table 1. This data set comprises a wide range of milk compositions, representative of the variation in individual milk samples that has also been observed by other researchers (Walstra et al., 1999).

To determine the actual prediction performance of a calculated model, the model should be evaluated on an independent test set that is representative of future samples. Table 2 shows the statistical parameters of the independent test set, which are similar to the ones for the calibration set. This indicates that the selection of the calibration and test set using the duplex algorithm worked well. Both Tables 1 and 2 show that no significant correlations were observed between components in the calibration and test set. The strongest correlation was noticed between milk fat and $\mathrm{CP}$ content $\left(\mathrm{R}^{2}=\right.$ 0.21 in the calibration set and 0.37 in the test set), probably caused by their genetic correlation (Rosati and Van Vleck, 2002). A very weak negative correlation was found between milk lactose content and the common logarithm of SCC $\left(\mathrm{R}^{2}=0.20\right.$ in the calibration set and 0.30 in the test set). This correlation is likely related to the occurrence of mastitis, causing a decrease in lactose content and a rise in SCC of the milk (Bansal et al., 2005). Due to the absence of strong correlations, the restrictions for the (Euclidian distance) duplex algorithm were fulfilled.

\section{Vis/NIR Spectra}

The raw reflectance and transmittance spectra for 5 milk samples with different fat contents are illustrated in Figures 1 and 2, respectively. Very low reflectance and transmittance values were recorded around 970, $1,190,1,450$, and $1,950 \mathrm{~nm}$ and above $2,400 \mathrm{~nm}$ because of the high absorbance by water. The undulating shape of the transmittance spectra, especially in the short wavelength range, is caused by absorption by the white reference. The milk absorbance spectra (after logarithmic transformation of reflectance and transmittance) for the raw milk samples were dominated by these strong water absorption bands. As a result, the characteristic absorption bands of fat, protein, and lactose were much weaker and even hard to detect. In Figures 3 and 4, the mean-centered first Savitzky-Golay derivatives of absorbance are illustrated for reflectance and transmittance spectra, respectively. Thanks to this preprocessing, the absorption bands for fat (930 and 1,690 $\mathrm{nm})$ and $\mathrm{CP}(1,650$ and 2,160 $\mathrm{nm}$ ) can be detected.

Overall, the reflectance spectra shifted upwards if the fat content increased (Figure 1), especially above 1,000 $\mathrm{nm}$, whereas the transmittance of milk above $1,000 \mathrm{~nm}$ decreased with increasing fat content (Figure 2). Different preprocessing methods were empirically tested before PLS calibration to remove the effect of these changing physical milk properties (scattering) on the measured spectra.

\section{PLS Calibration Models}

The spectral preprocessing, variable selection, and number of latent variables selected using the procedure described above, are summarized in Tables 3, 4, and 5 , together with the corresponding prediction performance for fat, $\mathrm{CP}$, and lactose, respectively. RMSEP with different subscripts indicate a significant difference between 2 classes according to the Tukey Honestly Significant Difference multiple comparison.

From Table 3, it can be observed that the best prediction of the fat content in raw milk was obtained when using the NIR $(1,000-2,500 \mathrm{~nm})$ transmittance spectra. Despite the rather large number of latent variables (9) selected, the PLS model performed very well (RPD = 17.7) on the test set (Figure 5). However, this best model was found not to be significantly better than the models using full $(400-2,500 \mathrm{~nm})$ transmittance, full 
Table 3. Model statistics for fat content prediction, together with the multiple comparisons between different classes based on the absolute prediction errors for the independent test set

\begin{tabular}{|c|c|c|c|c|c|c|c|c|c|c|c|}
\hline \multirow[b]{2}{*}{ Class } & \multirow[b]{2}{*}{ Preprocessing $^{1}$} & \multirow{2}{*}{$\begin{array}{l}\text { Variable } \\
\text { selection }{ }^{2}\end{array}$} & \multirow[b]{2}{*}{$L V^{3}$} & \multicolumn{2}{|c|}{ Cross-validation } & \multicolumn{6}{|c|}{ Validation } \\
\hline & & & & RMSECV $^{4}$ & $\mathrm{R}^{2}$ & RMSEP $^{5}$ & $\mathrm{R}^{2}$ & $\mathrm{RPD}^{6}$ & Bias & Slope & Offset \\
\hline Reflectance, $400-1,700 \mathrm{~nm}$ & $\begin{array}{l}\text { Reflectance; } \\
\text { SG2D(45); OSC }\end{array}$ & FiPLS & 3 & 0.042 & 0.997 & $0.052^{\mathrm{a}, \mathrm{b}}$ & 0.996 & 15.41 & 0.017 & 0.994 & 0.012 \\
\hline Reflectance, $400-1,000 \mathrm{~nm}$ & $\begin{array}{l}\text { Absorbance; } \\
\text { SG1D(15); OSC }\end{array}$ & FiPLS & 8 & 0.098 & 0.984 & $0.119^{\mathrm{b}}$ & 0.978 & 6.78 & 0.077 & 0.994 & -0.050 \\
\hline Reflectance, $1,000-1,700 \mathrm{~nm}$ & $\begin{array}{l}\text { Reflectance; } \\
\text { SG1D(27); OSC }\end{array}$ & GenAl & 2 & 0.049 & 0.996 & $0.047^{\mathrm{a}}$ & 0.997 & 17.22 & 0.004 & 1.005 & -0.028 \\
\hline Transmittance, $400-2,500 \mathrm{~nm}$ & $\begin{array}{l}\text { Absorbance; } \\
\text { SG1D(39); OSC }\end{array}$ & FiPLS & 3 & 0.058 & 0.994 & $0.070^{\mathrm{a}, \mathrm{b}}$ & 0.992 & 11.47 & -0.016 & 1.004 & 0.000 \\
\hline Transmittance, $400-1,700 \mathrm{~nm}$ & $\begin{array}{l}\text { Absorbance; } \\
\text { SG1D(27); OSC }\end{array}$ & RiPLS & 5 & 0.075 & 0.991 & $0.100^{\mathrm{a}, \mathrm{b}}$ & 0.982 & 7.39 & 0.026 & 0.968 & 0.119 \\
\hline Transmittance, $400-1,000 \mathrm{~nm}$ & $\begin{array}{l}\text { Absorbance; } \\
\text { OSC }\end{array}$ & RiPLS & 17 & 0.264 & 0.886 & $0.629^{c}$ & 0.395 & 1.29 & -0.329 & 0.755 & 1.351 \\
\hline Transmittance, $1,000-2,500 \mathrm{~nm}$ & $\begin{array}{l}\text { Transmittance; } \\
\text { SNV }\end{array}$ & GenAl & 9 & 0.049 & 0.996 & $0.043^{\mathrm{a}}$ & 0.997 & 17.74 & -0.002 & 0.997 & 0.014 \\
\hline Transmittance, $1,000-1,700 \mathrm{~nm}$ & $\begin{array}{l}\text { Absorbance; } \\
\text { SG1D }(21)\end{array}$ & RiPLS & 10 & 0.078 & 0.990 & $0.110^{\mathrm{a}, \mathrm{b}}$ & 0.981 & 7.32 & 0.021 & 1.005 & -0.045 \\
\hline Transmittance, $1,700-2,500 \mathrm{~nm}$ & $\begin{array}{l}\text { Transmittance; } \\
\text { SNV }\end{array}$ & GenAl & 6 & 0.064 & 0.993 & $0.066^{\mathrm{a}, \mathrm{b}}$ & 0.992 & 11.51 & 0.033 & 0.998 & -0.022 \\
\hline
\end{tabular}

${ }^{a-c}$ Different superscript letters within a column indicate significant $(P \leq 0.05)$ differences according to the Tukey Honestly Significant Difference (HSD) multiple comparison. ${ }^{1} \operatorname{SG1D}(x)$ and $\operatorname{SG} 2 \mathrm{D}(x)=$ first and second Savitzky-Golay derivatives with second polynomial order and with a window size of $x$ nm; OSC $=$ orthogonal signal correction; SNV $=$ ¿. standard normal variates.

${ }^{2} \mathrm{FiPLS}$ and $\mathrm{RiPLS}=$ forward and reverse interval partial least squares; GenAl = genetic algorithms.

ف ${ }^{3} \mathrm{LV}=$ number of latent variables selected.

으 $\quad{ }^{4} \mathrm{RMSECV}=$ root mean square error of cross-validation (expressed in \%, wt/wt)

$\stackrel{\text { g }}{\underline{g}} \quad{ }^{5} \mathrm{RMSEP}=$ root mean square error of prediction (expressed in $\%$, wt/wt). 
Table 4. Model statistics for $\mathrm{CP}$ content prediction, together with the multiple comparisons between different classes based on the absolute prediction errors for the independent test set

\begin{tabular}{|c|c|c|c|c|c|c|c|c|c|c|c|}
\hline \multirow[b]{2}{*}{ Class } & \multirow[b]{2}{*}{ Preprocessing $^{1}$} & \multirow{2}{*}{$\begin{array}{l}\text { Variable } \\
\text { selection }^{2}\end{array}$} & \multirow[b]{2}{*}{$\mathrm{LV}^{3}$} & \multicolumn{2}{|c|}{ Cross-validation } & \multicolumn{6}{|c|}{ Validation } \\
\hline & & & & RMSECV $^{4}$ & $\mathrm{R}^{2}$ & $\mathrm{RMSEP}^{5}$ & $\mathrm{R}^{2}$ & $\mathrm{RPD}^{6}$ & Bias & Slope & Offset \\
\hline Reflectance, $400-1,700 \mathrm{~nm}$ & $\begin{array}{l}\text { Reflectance; } \\
\text { SG2D(45): OSC }\end{array}$ & RiPLS & 3 & 0.097 & 0.955 & $0.113^{\mathrm{a}, \mathrm{b}}$ & 0.947 & 4.34 & 0.021 & 0.969 & 0.095 \\
\hline Reflectance, $400-1,000 \mathrm{~nm}$ & $\begin{array}{l}\text { Kubelka-Munk; } \\
\text { SG2D(51); OSC }\end{array}$ & GenAl & 3 & 0.147 & 0.897 & $0.183^{\mathrm{b}}$ & 0.861 & 2.68 & -0.034 & 1.017 & -0.028 \\
\hline Reflectance, $1,000-1,700 \mathrm{~nm}$ & $\begin{array}{l}\text { Reflectance; } \\
\text { SG1D(15); OSC }\end{array}$ & GenAl & 2 & 0.115 & 0.937 & $0.099^{\mathrm{a}}$ & 0.959 & 4.92 & -0.011 & 0.987 & 0.058 \\
\hline Transmittance, $400-2,500 \mathrm{~nm}$ & $\begin{array}{l}\text { Transmittance; } \\
\text { SG1D(45); OSC }\end{array}$ & GenAl & 13 & 0.101 & 0.952 & $0.156^{\mathrm{b}}$ & 0.898 & 3.13 & -0.087 & 1.036 & -0.042 \\
\hline Transmittance, $400-1,700 \mathrm{~nm}$ & $\begin{array}{l}\text { Absorbance; } \\
\text { SG2D(51); OSC }\end{array}$ & RiPLS & 3 & 0.131 & 0.919 & $0.162^{\mathrm{b}}$ & 0.890 & 3.01 & 0.003 & 0.963 & 0.134 \\
\hline Transmittance, $400-1,000 \mathrm{~nm}$ & $\begin{array}{l}\text { Absorbance; } \\
\text { SG1D(15); OSC }\end{array}$ & FiPLS & 3 & 0.211 & 0.789 & $0.274^{\mathrm{c}}$ & 0.687 & 1.79 & -0.136 & 0.984 & 0.192 \\
\hline Transmittance, $1,000-2,500 \mathrm{~nm}$ & $\begin{array}{l}\text { Transmittance; } \\
\text { SG1D(21); OSC }\end{array}$ & GenAl & 3 & 0.120 & 0.931 & $0.133^{\mathrm{a}, \mathrm{b}}$ & 0.927 & 3.69 & -0.044 & 1.039 & -0.098 \\
\hline Transmittance, $1,000-1,700 \mathrm{~nm}$ & $\begin{array}{l}\text { Transmittance; } \\
\text { SG1D(21); OSC }\end{array}$ & RiPLS & 12 & 0.126 & 0.924 & $0.250^{\mathrm{c}}$ & 0.739 & 1.96 & 0.012 & 0.910 & 0.320 \\
\hline Transmittance, $1,700-2,500 \mathrm{~nm}$ & $\begin{array}{l}\text { Transmittance; } \\
\text { MSC }\end{array}$ & RiPLS & 7 & 0.226 & 0.757 & $0.195^{\mathrm{b}, \mathrm{c}}$ & 0.841 & 2.50 & -0.001 & 0.999 & 0.006 \\
\hline
\end{tabular}

${ }^{\mathrm{a}-\mathrm{c}}$ Different superscript letters within a column indicate significant $(P \leq 0.05)$ differences according to the Tukey Honestly Significant Difference (HSD) multiple comparison. ${ }^{1} \operatorname{SG1D}(x)$ and $\operatorname{SG2D}(x)=$ first and second Savitzky-Golay derivatives with second polynomial order and with a window size of $x$ nm; OSC $=$ orthogonal signal correction; MSC $=$ multiplicative scatter correction.

${ }^{2}$ FiPLS and RiPLS $=$ forward and reverse interval partial least squares; GenAl = genetic algorithms

${ }^{3} \mathrm{LV}=$ number of latent variables selected.

${ }^{4} \mathrm{RMSECV}=$ root mean square error of cross-validation (expressed in \%, wt/wt).

${ }^{5} \mathrm{RMSEP}=$ root mean square error of prediction (expressed in \%, wt/wt).

${ }^{6} \mathrm{RPD}=$ ratio of prediction error to standard deviation. 


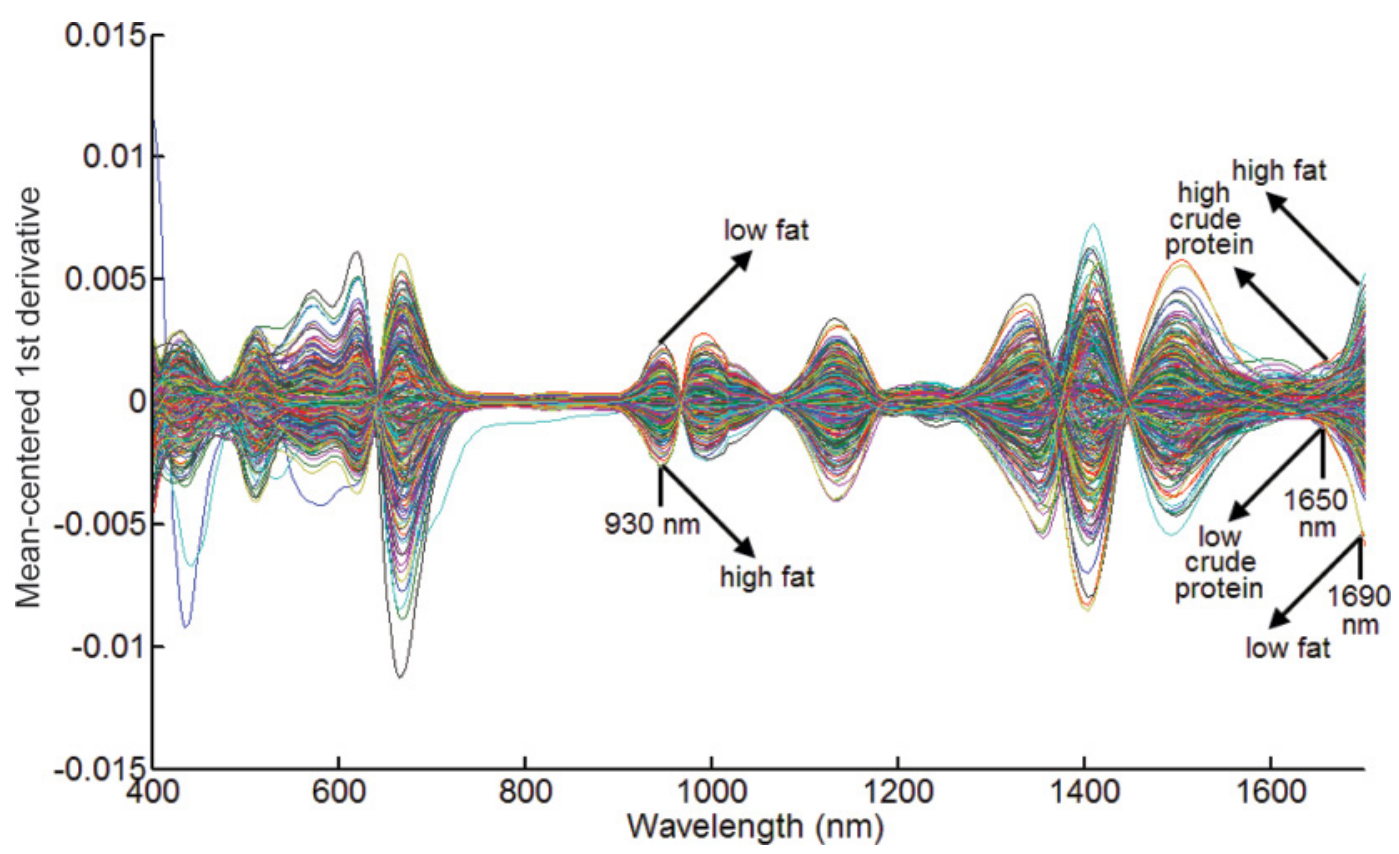

Figure 3. Mean-centered first Savitzky-Golay derivative of absorbance derived from reflectance spectra (400-1,700 nm) of 300 raw milk samples, with the most important absorption bands for fat and CP. Color version available in the online PDF.

(400-1,700 nm) reflectance, reduced NIR (1,000-1,700 $\mathrm{nm}$ or $1,700-2,500 \mathrm{~nm})$ transmittance, or reduced NIR $(1,000-1,700 \mathrm{~nm})$ reflectance spectra (Figure 5). All of these models obtained an RPD larger than 7.3, indi- cating that these models are very suitable for process control (Saeys et al., 2005). The short wavelength range $(400-1,000 \mathrm{~nm})$ resulted in significantly worse results for both reflectance and transmittance. Nevertheless,

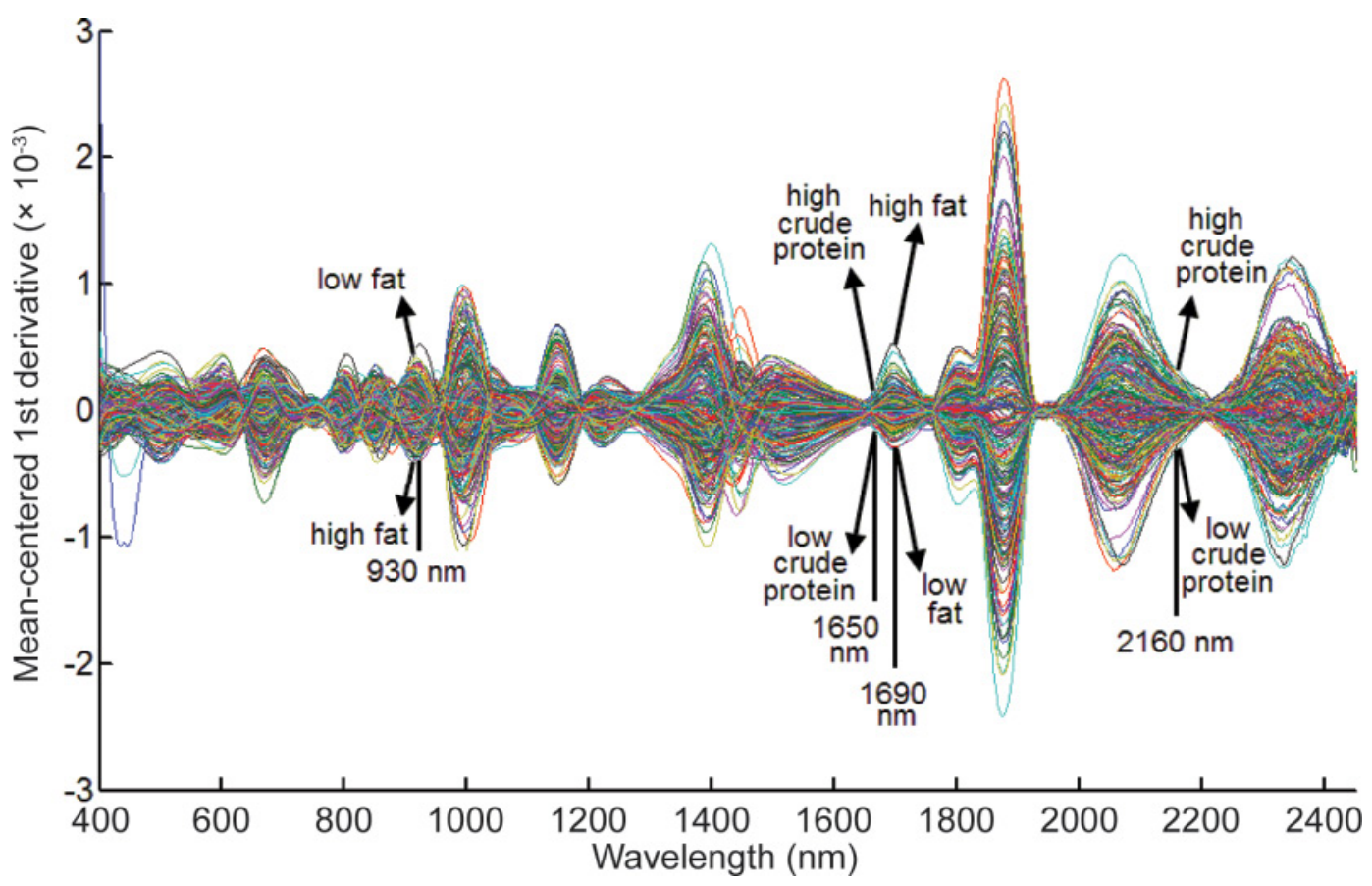

Figure 4. Mean-centered first Savitzky-Golay derivative of absorbance derived from transmittance spectra (400-2,450 nm) of 300 raw milk samples, with the most important absorption bands for fat and CP. Color version available in the online PDF. 
Table 5. Model statistics for lactose content prediction, together with the multiple comparison between different classes based on the absolute prediction errors for the independent test set

\begin{tabular}{|c|c|c|c|c|c|c|c|c|c|c|c|}
\hline \multirow[b]{2}{*}{ Class } & \multirow[b]{2}{*}{ Preprocessing $^{1}$} & \multirow{2}{*}{$\begin{array}{l}\text { Variable } \\
\text { selection }^{2}\end{array}$} & \multirow[b]{2}{*}{$\mathrm{LV}^{3}$} & \multicolumn{2}{|c|}{ Cross-validation } & \multicolumn{6}{|c|}{ Validation } \\
\hline & & & & $\mathrm{RMSECV}^{4}$ & $\mathrm{R}^{2}$ & RMSEP $^{5}$ & $\mathrm{R}^{2}$ & $\mathrm{RPD}^{6}$ & Bias & Slope & Offset \\
\hline Reflectance, $400-1,700 \mathrm{~nm}$ & $\begin{array}{l}\text { Reflectance; } \\
\text { SG2D(51); OSC }\end{array}$ & FiPLS & 2 & 0.166 & 0.720 & $0.182^{\mathrm{a}, \mathrm{b}}$ & 0.708 & 1.85 & 0.059 & 1.131 & -0.667 \\
\hline Reflectance, 400-1,000 nm & $\begin{array}{l}\text { Kubelka-Munk; } \\
\text { SG1D(21); OSC }\end{array}$ & FiPLS & 3 & 0.230 & 0.465 & $0.224^{\mathrm{b}}$ & 0.557 & 1.50 & 0.020 & 0.937 & 0.273 \\
\hline Reflectance, $1,000-1,700 \mathrm{~nm}$ & $\begin{array}{l}\text { Reflectance; } \\
\text { SG1D(09); OSC }\end{array}$ & None & 2 & 0.177 & 0.681 & $0.282^{b, c}$ & 0.300 & 1.19 & -0.011 & 0.619 & 1.759 \\
\hline Transmittance, $400-2,500 \mathrm{~nm}$ & $\begin{array}{l}\text { Transmittance; } \\
\text { SG1D(39); OSC }\end{array}$ & GenAl & 14 & 0.103 & 0.893 & $0.164^{\mathrm{a}, \mathrm{b}}$ & 0.761 & 2.05 & 0.095 & 0.989 & -0.044 \\
\hline Transmittance, $400-1,700 \mathrm{~nm}$ & $\begin{array}{l}\text { Absorbance; } \\
\text { SG1D(27); OSC }\end{array}$ & RiPLS & 9 & 0.091 & 0.916 & $0.115^{\mathrm{a}}$ & 0.883 & 2.92 & -0.043 & 0.932 & 0.353 \\
\hline Transmittance, $400-1,000 \mathrm{~nm}$ & $\begin{array}{l}\text { Absorbance; } \\
\text { SG2D(45); OSC }\end{array}$ & None & 3 & 0.232 & 0.453 & $0.317^{\mathrm{c}}$ & 0.111 & 1.06 & 0.055 & 0.568 & 1.958 \\
\hline Transmittance, $1,000-2,500 \mathrm{~nm}$ & $\begin{array}{l}\text { Transmittance; } \\
\text { SG1D(21); OSC }\end{array}$ & RiPLS & 8 & 0.106 & 0.886 & $0.162^{\mathrm{a}, \mathrm{b}}$ & 0.768 & 2.07 & -0.011 & 0.974 & 0.130 \\
\hline Transmittance, $1,000-1,700 \mathrm{~nm}$ & $\begin{array}{l}\text { Absorbance; } \\
\text { SG1D(33); OSC }\end{array}$ & None & 3 & 0.111 & 0.875 & $0.128^{\mathrm{a}}$ & 0.856 & 2.64 & -0.049 & 0.954 & 0.260 \\
\hline Transmittance, $1,700-2,500 \mathrm{~nm}$ & $\begin{array}{l}\text { Absorbance; } \\
\text { SG1D(51); OSC }\end{array}$ & FiPLS & 2 & 0.263 & 0.297 & $0.328^{\mathrm{c}}$ & 0.050 & 1.03 & 0.005 & 0.539 & 2.116 \\
\hline
\end{tabular}

${ }^{a-c}$ Different superscript letters within a column indicate significant $(P \leq 0.05)$ differences according to the Tukey Honestly Significant Difference (HSD) multiple comparison. ${ }^{1} \operatorname{SG1D}(x)$ and $\operatorname{SG2D}(x)=$ first and second Savitzky-Golay derivatives with second polynomial order and with a window size of $x$ nm; OSC $=$ orthogonal signal correction. ${ }^{2} \mathrm{FiPLS}$ and RiPLS $=$ forward and reverse interval partial least squares; GenAl = genetic algorithms.

${ }^{3} \mathrm{LV}=$ number of latent variables selected.

${ }^{4} \mathrm{RMSECV}=$ root mean square error of cross-validation (expressed in \%, wt/wt).

${ }^{5} \mathrm{RMSEP}=$ root mean square error of prediction (expressed in $\%$, wt $/ \mathrm{wt}$ ).

${ }^{6} \mathrm{RPD}=$ ratio of prediction error to standard deviation. 

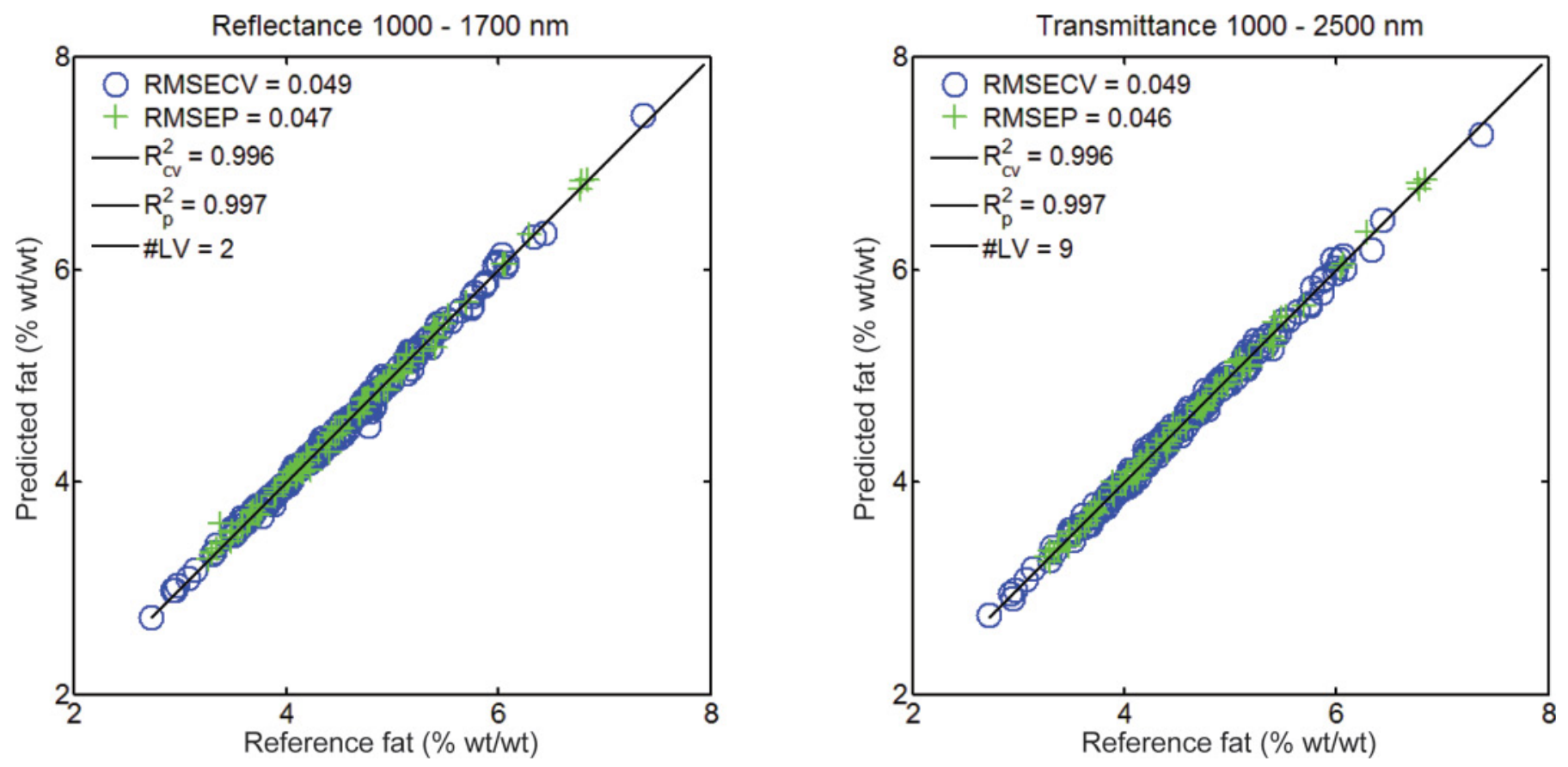

Figure 5. Scatter plots of the predicted versus reference fat content for both cross-validation (circles) and validation on the test set (crosses) for reflectance (left) and transmittance (right). The best wavelength range and spectral pretreatment were considered (Table 3). RMSECV = root mean square error of cross-validation; RMSEP = root mean square error of prediction; $\mathrm{R}_{\mathrm{cy}}^{2}=$ coefficient of determination for cross-validation; $\mathrm{R}_{\mathrm{P}}^{2}=$ coefficient of determination for prediction; $\# \mathrm{LV}=$ number of selected latent variables. Color version available in the online PDF.

the use of the reflectance mode still resulted in an RPD value of 6.8 using only that spectral range, whereas the prediction performance for transmittance mode was unacceptable $(\mathrm{RPD}=1.3)$.

For CP prediction (Table 4), the best results were obtained using the 1,000 to 1,700-nm reflectance spectra $(\mathrm{RPD}=4.9)$. This model was not significantly better than those based on full $(400-1,700 \mathrm{~nm})$ reflectance and 1,000 to 2,500-nm transmittance measurements (Figure 6), with all 3 RPD above 3.7. All 3 PLS models are expected to be robust, as a maximum of 3 latent variables were selected. These models give sufficient prediction accuracy for monitoring the protein content in raw milk. Although the prediction performance for full $(400-2,500 \mathrm{~nm})$ and reduced $(400-1,700 \mathrm{~nm})$ transmittance spectra was significantly worse, these spectra can be used for rough monitoring $(\mathrm{RPD} \approx 3)$ of the protein content in raw milk (Saeys et al., 2005). However, many latent variables (13) were selected for the model based on the full transmittance spectra, representing a larger risk for poor robustness. Again, the shorter wavelength range (400-1,000 nm) for both reflectance and transmittance gave rather poor prediction results, as well as the 1,000 to $1,700-$ and 1,700 to $2,500-\mathrm{nm}$ transmittance spectra (all RPD $\leq 2.7$ ).

Table 5 shows the best models for prediction of the lactose content with Vis/NIR reflectance and transmit- tance spectroscopy. Again a strong effect of measurement mode and wavelength range (class) was observed on the prediction results. The PLS model using the 400 to 1,700-nm transmittance spectra (Figure 7) resulted in the best prediction ( $\mathrm{RPD}=2.9)$, whereas reducing these spectra to the 1,000 to $1,700-\mathrm{nm}$ range did not significantly influence the prediction performance $(\mathrm{RPD}=2.6)$. Both models allow for rough screening of the lactose content in raw milk (Saeys et al., 2005). Although no significant difference was found between the 2 best models described above and the models based on full transmittance, full reflectance (Figure 7) and 1,000 to 2,500-nm transmittance spectra, the latter were insufficient for lactose prediction $(\mathrm{RPD} \leq 2.1)$. The remaining classes performed significantly worse compared with the best model and are, therefore, unacceptable.

The determination of urea in milk seemed not possible with Vis/NIR reflectance or transmittance spectroscopy, resulting in RPD values below 1.2 for all classes (results not shown).

In most cases, the best spectral preprocessing method was a combination of Savitzky-Golay derivatives (both first and second derivatives with different number of smoothing points), followed by orthogonal signal correction. Different variable selection methods were selected, except for variable importance in projection. 

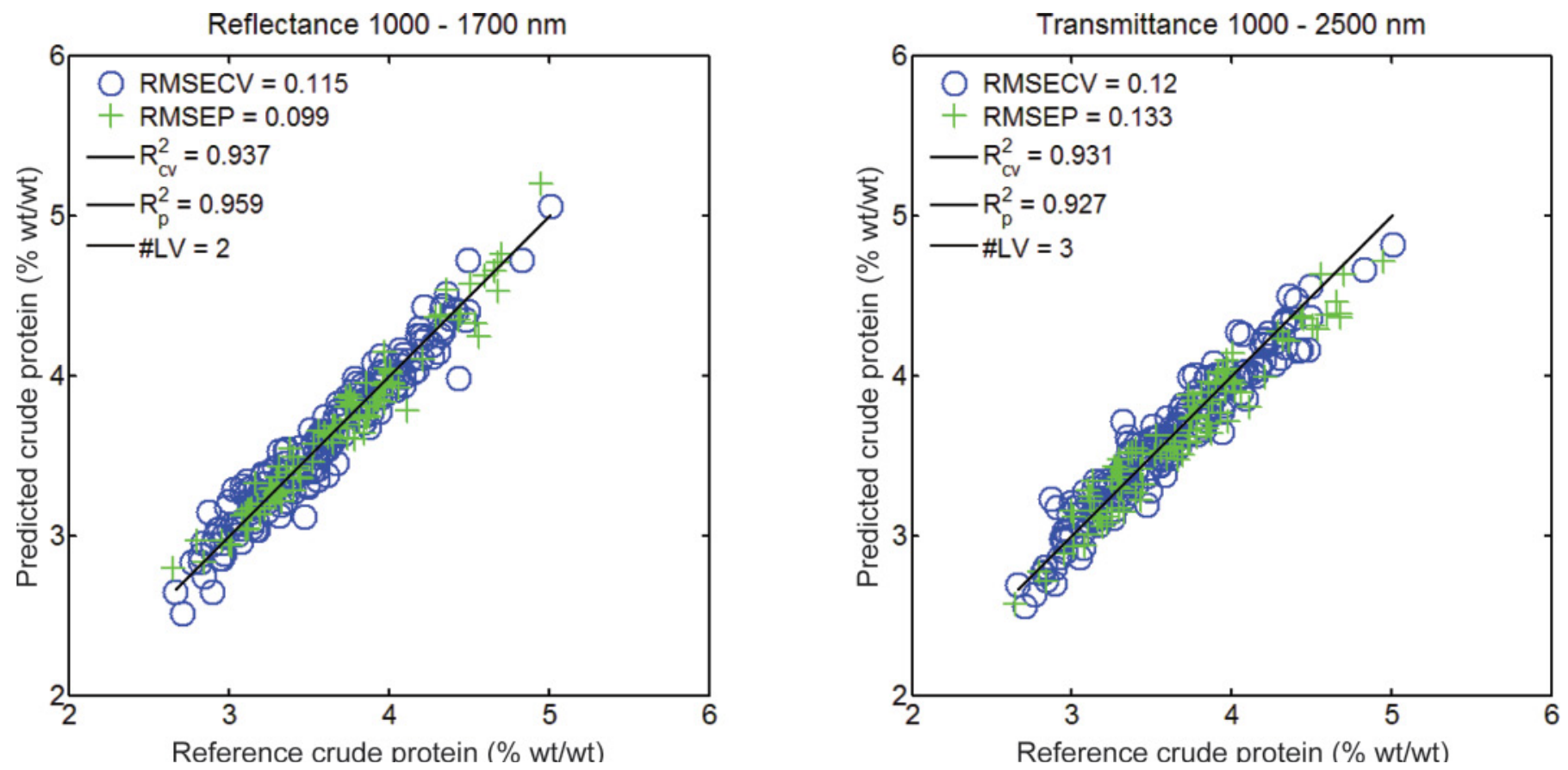

Figure 6. Scatter plots of the predicted versus reference CP content for both cross-validation (circles) and validation on the test set (crosses) for reflectance (left) and transmittance (right). The best wavelength range and spectral pretreatment were considered (Table 4). RMSECV $=$ root mean square error of cross-validation; RMSEP $=$ root mean square error of prediction; $\mathrm{R}_{\mathrm{cv}}^{2}=$ coefficient of determination for cross-validation; $\mathrm{R}_{\mathrm{P}}^{2}=$ coefficient of determination for prediction; \#LV = number of selected latent variables. Color version available in the online PDF.
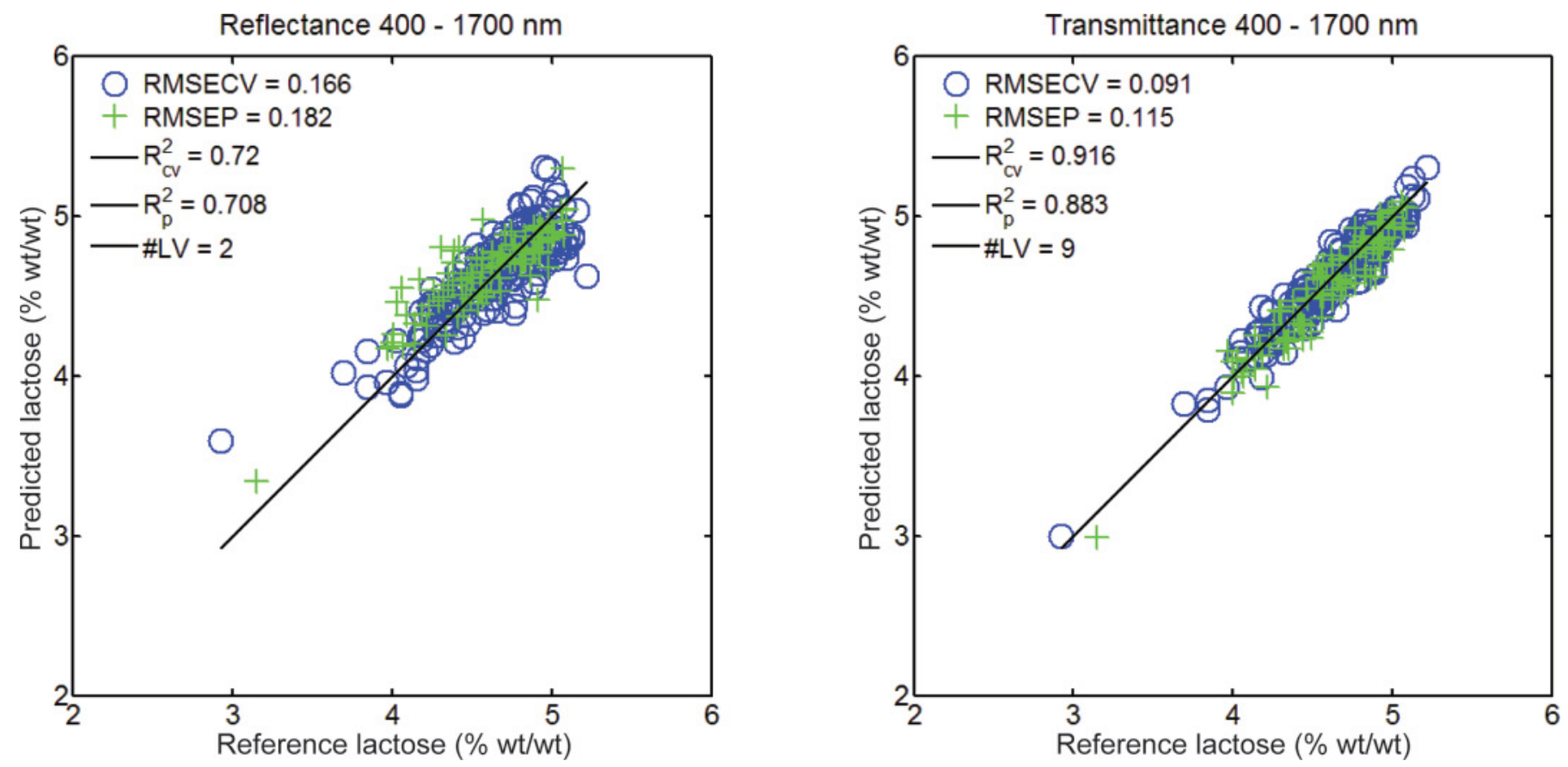

Figure 7. Scatter plots of the predicted versus reference lactose content for both cross-validation (circles) and validation on the test set (crosses) for reflectance (left) and transmittance (right). The best wavelength range and spectral pretreatment were considered (Table 5). $\mathrm{RMSECV}=$ root mean square error of cross-validation; RMSEP $=$ root mean square error of prediction; $\mathrm{R}_{\mathrm{cv}}^{2}=$ coefficient of determination for cross-validation; $\mathrm{R}_{\mathrm{P}}^{2}=$ coefficient of determination for prediction; $\# \mathrm{LV}=$ number of selected latent variables. Color version available in the online PDF. 


\section{DISCUSSION}

Reflectance spectra led to very good predictions for fat content in raw milk, especially for the NIR $(1,000$ $1,700 \mathrm{~nm}$ ) region (Figure 5). This is probably thanks to a combination of absorption and scattering of the light by fat globules in this spectral range. In the NIR region, an overall rather high positive correlation $\left(\mathrm{R}^{2}>0.45\right)$ existed between the reflectance values and the fat content. These scatter phenomena are most likely caused by fat globules whose size and number are related to the milk fat content (Wiking et al., 2004). High fat content results in more and larger scatterers (fat globules), presumably reflecting more light in the direction of the light source. Besides this, high coefficients for the PLS regression vector were found around $930 \mathrm{~nm}$ (Figures 3 and 4), indicating the third overtone $\mathrm{C}-\mathrm{H}$ stretch vibrations of triglycerides (Šašić and Ozaki, 2001; van der Meer and de Jong, 2001).

The NIR (1,000-2,500 nm) transmittance spectra resulted in even better predictions (not significant) for fat (Figure 5). In this range, an overall negative correlation $\left(\mathrm{R}^{2}>0.5\right)$ was found between transmittance and fat content. This indicates that the fat globules are responsible for back-scattering a significant part of the light in the direction of the light source, resulting in a higher reflectance and lower transmittance for fatty milk samples. Absorption of NIR radiation by the first overtone of $\mathrm{C}-\mathrm{H}$ stretch vibrations occurred between 1,660 and 1,730 nm (Šašić and Ozaki, 2001), indicated by high PLS regression coefficients for fat prediction based on the transmittance spectra (Figure 4). The short wavelength range $(400-1,000 \mathrm{~nm})$ seemed to be less informative for the fat prediction, as this spectral range alone resulted in significantly worse results, and adding this range to the NIR range did not improve the results. The transmittance in the short wavelength range was inadequate even for rough estimation of the fat content. This was unexpected, as Tsenkova et al. (1999) and Saranwong and Kawano (2008) obtained good results for this wavelength range. Our insufficient predictions might be explained by the sample thickness, which was not optimized for the short wavelength range (Tsenkova et al., 1999) in combination with small instabilities of the light source observed in the visible range.

The prediction results for $\mathrm{CP}$ were worse than those for fat, but the best results were still very useful. The ranges 1,000 to $1,700 \mathrm{~nm}$ for reflectance and 1,000 to $2,500 \mathrm{~nm}$ for transmittance were found to be very informative for $\mathrm{CP}$ detection in milk (Figure 6), probably because this range included the first-overtone amide $\mathrm{B}$ absorption band (Figures 3 and 4) at 1,640 to 1,670 nm (Czarnik-Matusewicz et al.,1999). For the transmittance spectra, high PLS regression coefficients were also found at 2,160 nm (Figure 4), corresponding to the amide B and amide II absorption bands (Stuart and Ando, 1997).

Lactose prediction was not possible based on the reflectance spectra. A possible explanation might be an insufficient interaction between the lactose, which is diluted in the milk serum, and the Vis/NIR radiation, which is reflected back in the direction of the light source. Probably, a large part of the incident radiation is reflected directly by the fat globules and CN micelles in milk before it can penetrate into the sample, especially in the short wavelength range (reflectance up to $80 \%$ ). Above $1,200 \mathrm{~nm}$, the reflectance is very low because most of the radiation is absorbed by water. For transmittance, however, the 1,000 to $1,700 \mathrm{~nm}$ range was found to contain a lot of information on the lactose content. The region 1,480 to $1,500 \mathrm{~nm}$ was important, including the first overtone for $\mathrm{O}-\mathrm{H}$ stretch vibrations for sugars at 1,490 nm (Stuart and Ando, 1997). Extending this 1,000 to $1,700-n m$ range with the short wavelength spectra did improve the prediction results for lactose (Figure 7), but this improvement was not significant. Moreover, the model structure became more complex (9 latent variables instead of 3 ) and, therefore, probably less robust.

The prediction performances for fat, CP, and lactose content in raw milk obtained in this study based on transmittance spectra are comparable to those reported by other researchers (Laporte and Paquin, 1999; Purnomoadi et al., 1999; Tsenkova et al., 1999; Navrátilová et al., 2006; Saranwong and Kawano, 2008). Although Si detectors have become relatively inexpensive and are widely used, the spectral range that can be accessed with these (400-1,000 nm) was found to be not so interesting for milk composition prediction. The only potential application identified in this study is prediction of the fat content from measurements in reflectance mode. Tsenkova et al. (1999) also reported that the 1,000 to $2,500-\mathrm{nm}$ range was more informative on the raw milk composition than the shorter wavelength range. The major drawback of transmittance measurements in the 1,000 to $2,500-\mathrm{nm}$ range is the need for a short path length $(1 \mathrm{~mm})$, due to the high absorption by water and the strong light scattering by the fat globules in this range. This considerably complicates its use online.

The prediction accuracies obtained in reflectance mode are in accordance with the findings of Jankovská and Šustová (2003), who obtained coefficient of determination for cross-validation $\left(\mathrm{R}_{\mathrm{CV}}^{2}\right)$ values of $0.91,0.90$, and 0.56 for the prediction of fat, $\mathrm{CP}$, and lactose, respectively.

Some researchers also tried to predict the urea content of raw milk with Vis/NIR spectroscopy. Jankovská 
and Šustová (2003) and Kawasaki et al. (2008) obtained inadequate results with coefficient of determination below 0.68 for an independent test set. This is most likely due to the low concentrations of urea $(50-450 \mathrm{mg} / \mathrm{L})$ and, consequently, a low Vis/NIR absorbance by urea in milk. Moreover, the most important NIR absorption peaks for urea are located in a region having a high absorption by water $(1,990-2,250 \mathrm{~nm}$; Workman and Weyer, 2007). Nevertheless, Kawamura et al. (2007) reported very good results $\left(\mathrm{R}^{2}=0.9\right)$ for urea prediction for an independent set of milk samples by using only the short wavelength range $(600-1,050 \mathrm{~nm})$.

\section{CONCLUSIONS}

In this study, the potential of 2 measurement modes of Vis/NIR spectroscopy was evaluated and compared for the analysis of raw milk composition. Different wavelength ranges were considered and evaluated as a second factor influencing the accuracy for predicting the different milk components. The NIR $(1,000-1,700$ $\mathrm{nm})$ reflectance measurements combine a very high accuracy for fat and CP prediction with a simple measurement configuration, which is highly suitable for online measurements of highly turbid fluids, but gave poor results for lactose prediction. If accurate measurement of the lactose content in the produced milk is needed, NIR (1,000-2,500 nm), transmittance measurements through $1 \mathrm{~mm}$ of milk would be the best option. This would allow for monitoring all 3 important milk components (fat, protein, and lactose) with sufficient accuracy. However, the requirement for a small path length $(1 \mathrm{~mm})$ would considerably complicate online use. The short wavelength $(400-1,000)$ range, which can be accessed with relatively inexpensive Si detectors, was found not to be sufficient for accurate monitoring of the milk composition.

\section{ACKNOWLEDGMENTS}

The authors thank Milk Control Centre Flanders (MCC-Vlaanderen, Lier, Belgium) for providing the milk samples and their reference analyses. Ben Aernouts and Wouter Saeys are respectively funded as aspirant and postdoctoral fellow of the Research FoundationFlanders (Brussels, Belgium). Evgeny Polshin is funded through a grant from the Erasmus Mundus External Cooperation Window mobility scheme with Russia.

\section{REFERENCES}

Bansal, B. K., J. Hamann, N. T. Grabowski, and K. B. Singh. 2005. Variation in the composition of selected milk fraction samples from healthy and mastitic quarters, and its significance for mastitis diagnosis. J. Dairy Res. 72:144-152.
Barabássy, S. 2001. The application of near infrared spectroscopy (NIR) technique for non-destructive investigation of mixed milk powder products. Mljekarstvo 51:263-272.

Bramley, A. J., F. H. Dodd, G. A. Mein, and J. A. Bramley. 1992. Machine Milking and Lactation. Insight Books, Berkshire, UK.

Cederkvist, H. R., A. H. Aastveit, and T. Næs. 2005. A comparison of methods for testing differences in predictive ability. J. Chemometrics 19:500-509.

Czarnik-Matusewicz, B., K. Murayama, R. Tsenkova, and Y. Ozaki. 1999. Analysis of near-infrared spectra of complicated biological fluids by two-dimensional correlation spectroscopy: Protein and fat concentration-dependent spectral changes of milk. Appl. Spectrosc. $53: 1582-1594$.

Frank, B., and C. Swensson. 2002. Relationship between content of crude protein in rations for dairy cows and milk yield, concentration of urea in milk and ammonia emissions. J. Dairy Sci. $85: 1829-1838$

Friggens, N. C., C. Ridder, and P. Løvendahl. 2007. On the use of milk composition measures to predict the energy balance of dairy cows. J. Dairy Sci. 90:5453-5467.

Haaland, D. M., and E. V. Thomas. 1988. Partial least-square methods for spectral analysis. 1. Relation to other quantitative calibration methods and the extraction of qualitative information. Anal. Chem. 60:1193-1202.

Hamann, J., and V. Krömker. 1997. Potential of specific milk composition variables for cow health management. Livest. Prod. Sci 48:201-208.

Huang, H., H. Yu, H. Xu, and Y. Ying. 2008. Near infrared spectroscopy for on/in-line monitoring of quality in foods and beverages: A review. J. Food Eng. 87:303-313.

ISO (International Organization for Standardization). 2000. Whole milk-Determination of milk fat, protein and lactose contentGuidance on the operation of mid-infrared instruments. International Standard ISO 9622:2000/IDF 141C:2000. International Dairy Federation, Brussels, Belgium.

Jankovská, R., and K. Šustová. 2003. Analysis of cow milk by nearinfrared spectroscopy. Czech J. Food Sci. 21:123-128.

Kawamura, S., M. Kawasaki, H. Nakatsuji, and M. Natsuga. 2007. Near-infrared spectroscopic sensing system for online monitoring of milk quality during milking. Sens. Instrum. Food Qual. Saf. $1: 37-43$.

Kawasaki, M., S. Kawamura, M. Tsukahara, S. Morita, M. Komiya, and M. Natsuga. 2008. Near-infrared spectroscopic sensing system for on-line milk quality assessment in a milking robot. Comput. Electron. Agric. 63:22-27.

Laporte, M.-F., and P. Paquin. 1999. Near-infrared analysis of fat protein, and casein in cow's milk. J. Agric. Food Chem. 47:26002605

Mulligan, F. J., L. O'Grady, D. A. Rice, and M. L. Doherty. 2006. A herd health approach to dairy cow nutrition and production diseases of the transition cow. Anim. Reprod. Sci. 96:331-353.

Navrátilová, P., L. Hadra, M. Dračková, B. Janštová, L. Vorlová, and L. Pavlata. 2006. Use of FT-NIR spectroscopy for bovine colostrum analysis. Acta Vet. (Brno) 75:57-63.

Nicolaï, B. M., K. Beullens, E. Bobelyn, A. Peirs, W. Saeys, K. I. Theron, and J. Lammertyn. 2007. Nondestructive measurement of fruit and vegetable quality by means of NIR spectroscopy: A review. Postharvest Biol. Technol. 46:99-118.

O'Callaghan, D. J., C. P. O'Donnell, and F. A. Payne. 2002. Review of systems for monitoring curd setting during cheese making. Int J. Dairy Technol. 55:65-74.

Plaizier, J. C., D. O. Krause, G. N. Gozho, and B. W. McBride. 2008. Subacute ruminal acidosis in dairy cows: The physiological causes, incidence and consequences. Vet. J. 176:21-31.

Purnomoadi, A., K. K. Batajoo, K. Ueda, and F. Terada. 1999. Influence of feed source on determination of fat and protein in milk by near-infrared spectroscopy. Int. Dairy J. 9:447-452.

Rosati, A., and L. D. Van Vleck. 2002. Estimation of genetic parameters for milk, fat, protein and mozzarella cheese production for the Italian river buffalo Bubalus bubalis population. Livest. Prod. Sci. $74: 185-190$. 
Saeys, W., K. Beullens, J. Lammertyn, H. Ramon, and T. Naes. 2008. Increasing robustness against changes in the interferent structure by incorporating prior information in the augmented classical least-squares framework. Anal. Chem. 80:4951-4959.

Saeys, W., A. M. Mouazen, and H. Ramon. 2005. Potential for on-site and on-line analysis of pig manure using visual and near-infrared reflectance spectroscopy. Biosystems Eng. 91:393-402.

Saranwong, S., and S. Kawano. 2008. System design for non-destructive near infrared analyses of chemical components and total aerobic bacteria count of raw milk. J. Near Infrared Spectrosc. 16:389-398.

Šašić, S., and Y. Ozaki. 2001. Short-wave near-infrared spectroscopy of biological fluids. 1. Quantitative analysis of fat, protein, and lactose in raw milk by partial least-squares regression and band assignment. Anal. Chem. 73:64-71.

Snee, R. D. 1977. Validation of regression models: Methods and examples. Technometrics 19:415-428.

Stuart, B., and D. J. Ando. 1997. Biological Applications of Infrared Spectroscopy. John Wiley and Sons Inc., New York, NY.

Tsenkova, R., S. Atanassova, K. Toyoda, Y. Ozaki, K. Itoh, and T. Fearn. 1999. Near infrared spectroscopy for dairy measurement:
Measurement of unhomogenized milk composition. J. Dairy Sci. $82: 2344-2351$.

van der Meer, F. D., and S. M. de Jong. 2001. Imaging Spectrometry: Basic Principles and Prospective Applications, Volume 1. Kluwer Academic Publishers, Dordrecht, the Netherlands.

Walstra, P., T. J. Geurts, A. Noomen, A. Jellema, and M. A. J. S. van Boekel. 1999. Dairy Technology: Principles of Milk Properties and Processes. Marcel Dekker Inc., New York, NY.

Wiking, J., J. Stagsted, L. Björck, and J. H. Nielsen. 2004. Milk fat globule size is affected by fat production in dairy cows. Int. Dairy J. 14:909-913.

Williams, P., and K. Norris. 2001. Near-Infrared Technology in the Agricultural and Food Industries. 2nd ed. American Association of Cereal Chemists, Saint Paul, MN.

Wise, B. M., N. B. Gallagher, R. Bro, J. M. Shaver, W. Windig, and R. S. Koch. 2006. PLS Toolbox 4.0 for use with MATLAB. Eigenvector Research Inc., Manson, MA.

Workman, J., and L. Weyer. 2007. Practical Guide to Interpretive Near-Infrared Spectroscopy. Taylor and Francis Group LLC, Boca Raton, FL. 